\title{
Simulation of Induction Traction Drive with Supercapacitor Energy Storage System Test Bench
}

\author{
Girts Stana (Doctoral student, Riga Technical University), Viesturs Brazis (Associate Professor, Riga Technical \\ University), Peteris Apse-Apsitis (Lead Researcher, Riga Technical University)
}

\begin{abstract}
The paper describes the application of supercapacitor energy storage system for induction traction drive test bench that replaces a real electric public transport for performing testing and researches. The suitability and usage of such bench for research purposes is explained and the importance of the development of software mathematical model for performing simulations to be done before physical implementation measures is reasoned. The working principle of the bench and applied components are described. A virtual model of the bench was built and simulations were performed using Matlab/Simulink software. The basic topology of the virtual bench model is described as well. The calculations of this work show the scaling of supercapacitor energy storage system by setting different limits of working voltage range in order to adjust them to test bench parameters, whereas the modelling compares two simulation cases - the application of less supercapacitors and the application of more supercapacitors with the same common rated voltage. The autonomous mode simulations were also performed. Simulation results are analyzed and recommendations for the application of the supercapacitor energy storage system, with respect to initial supercapacitor circuit voltage, are given.
\end{abstract}

Keywords - Energy storage; Motor drives; Traction motors; Traction power supply; Supercapacitors.

\section{INTRODUCTION}

Non-regenerative units of electric public transport (EPT) like trams and trolleybuses are gradually being taken out of exploitation because modern EPT usually is equipped with electric drive system which is regenerative and is able to deliver the braking energy back to supply grid. Further, this regenerated braking energy is used by other EPT that perform acceleration and are located in the same overhead grid section. If there is no other accelerating EPT the regenerated braking energy is transferred to the braking resistor and dissipated in heat which is economically disadvantageous from energy saving point of view.

The issue of achieving the situation when the braking energy is not transferred to braking resistors is very relevant in rational utilization and saving of electrical energy. The application of energy storage system (ESS) is a significant way of solving this problem. Energy storage elements can be mounted in power substations or installed on board of EPT.

It is possible to equip non-reversible substations with ESS. In this case, ESS can operate as the limiter of the maximum power of supply grid and also receive braking energy from several EPT units simultaneously. However, the main disadvantage is that the substations can be located at high distances. Consequently, significant amount of electrical energy could be lost in transfer wires.

For that reason, it is offered to apply onboard ESSs for EPT. Then energy transfer losses are not relevant. When the supply grid gets disconnected, onboard ESS can provide the necessary power in autonomous mode for certain time. In this context, energy storage elements are prescribed to be accumulator batteries and supercapacitors (SC). Accumulators are with high energy density and in general thought to supply EPT with power in comparatively long distances of autonomous mode. In comparison to accumulators, SCs have high power density and are more appropriate for braking energy storing and supply EPT with energy during fast accelerations. Therefore, this article focuses on ESS with SCs and accumulator batteries are not considered.

By producing a new EPT unit or improving existing ones, it is mandatory to perform test journeys. Some of this improvement includes equipping EPT with ESS as well. To decrease the number of test journeys, traction drive test benches that are of smaller scale but proportional to real EPT units are useful because their power is ten times lower than the power of real surface EPT and it is appropriate in university circumstances. Up to now, mainly direct current (DC) electric traction drive test benches have been studied [1], [2]. This article focuses on AC traction drive test bench the ESS of which must operate in the same way as the ESS of DC drive because AC traction drive is fed from conventional DC overhead network.

Before the physical realization of any laboratory test bench, a virtual model should be developed for carrying out various simulations to ensure that the bench is capable of work as such. Even the power in the range of 3-7.5 kW is considered to be dangerous in case of setting up incorrect parameters or control methods. Due to the virtual simulations of the bench, probable disaster or faults caused by physical realization could be prevented.

The aim of the research is to perform virtual simulations to inspect the working capability and efficiency of SC ESS when it is applied for supplying the test bench with energy during acceleration of traction motor and for storing the braking energy during deceleration of traction motor. Two cases are investigated - firstly, two series of SCs are connected, and secondly, another series of connection of two SCs is connected in parallel thus increasing the common capacitance twice. Theoretically, greater capacitance always ensures better efficiency of braking energy storing thus allowing close to full traction drive's braking energy storage. 


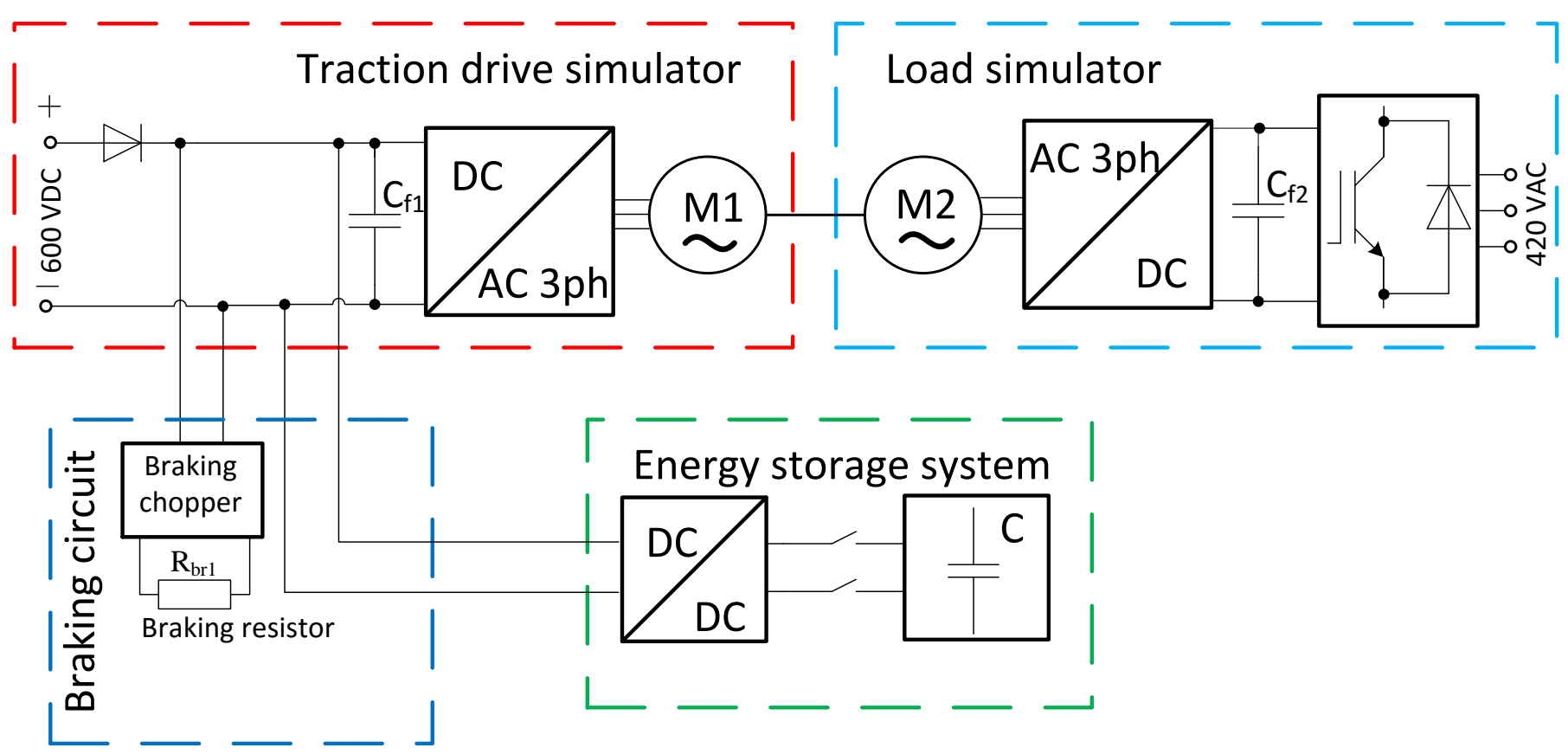

Fig. 1. Simplified diagram of the test bench.

On the other hand, smaller capacitance stands for a smaller number of SCs and that is cheaper from the point of view of exploitation prices.

AC traction drive was chosen due to the fact that in comparison to DC traction drive it was developed on the basis of standard industrial solutions. The role of ESS in AC drive is more significant because modern AC drives are more suitable for network voltage quality and instability.

\section{AC TRACTION DRIVE TEST BENCH}

Fig. 1 shows the scheme of AC traction drive test bench with two inverters, one reversible rectifier and two identical induction motors.

The main components of the bench are two identical coupled AC machines M1 and M2 the first of which imitates the traction of EPT and the second imitates the load or rolling stock of EPT. Direct torque control (DTC) frequency converters are applied for both motors containing torque controller for M1 and speed controller for M2 shown in more detail in Fig. 3. Fig. 1 shows only basic components, not, for example, electromagnetic torque sensor and its signal wire. Both M1 and M2 have rated power and rated speed that are $P_{\text {nom,bench }}=7.5 \mathrm{~kW}$ and $n=1440 \mathrm{rpm}$ accordingly. The working principle of the bench is explained in more detail in [3] but the main alteration made in this research is the reversible rectifier of the load simulator. During the traction mode of the bench electrical energy generated by M2 is transferred to AC grid. The ESS which includes two-quadrant reversible Buck-Boost DC/DC converter with several energy storage SC components is connected to the DC link of the traction drive simulator.

The Buck-Boost converter operates in buck mode at SC charging and boost mode at SC discharging. In the output of DC/DC converter two series of SCs are connected in one case and two such SC circuits are connected in parallel in other case. The SC operating voltage is chosen below the network voltage to avoid ESS voltages above the DC link voltage. 600 VDC network could be presumed to simulate a substation or DC grid. Fig. 2 shows a classic DC/DC converter that is applied for the bench.

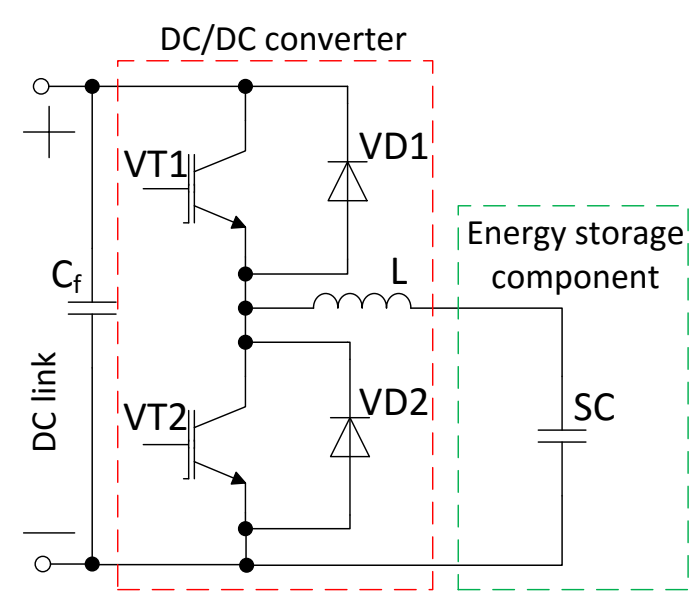

Fig. 2. Diagram of SC and DC/DC converter connection.

Boost mode is applied when traction motor accelerates by discharging ESS. During this mode VT1 and VD2 do not function but VT2 is switched on and off thus controlling the discharging rate of ESS. Buck mode is applied when traction motor decelerates by charging ESS. During this mode VT2 and VD1 do not function but VT1 is switched on and off thus controlling the charging rate of ESS. In traction drive generator mode braking resistor $R_{\text {brl }}$ circuit with its chopper works only if ESS gets disconnected or fully charged. 


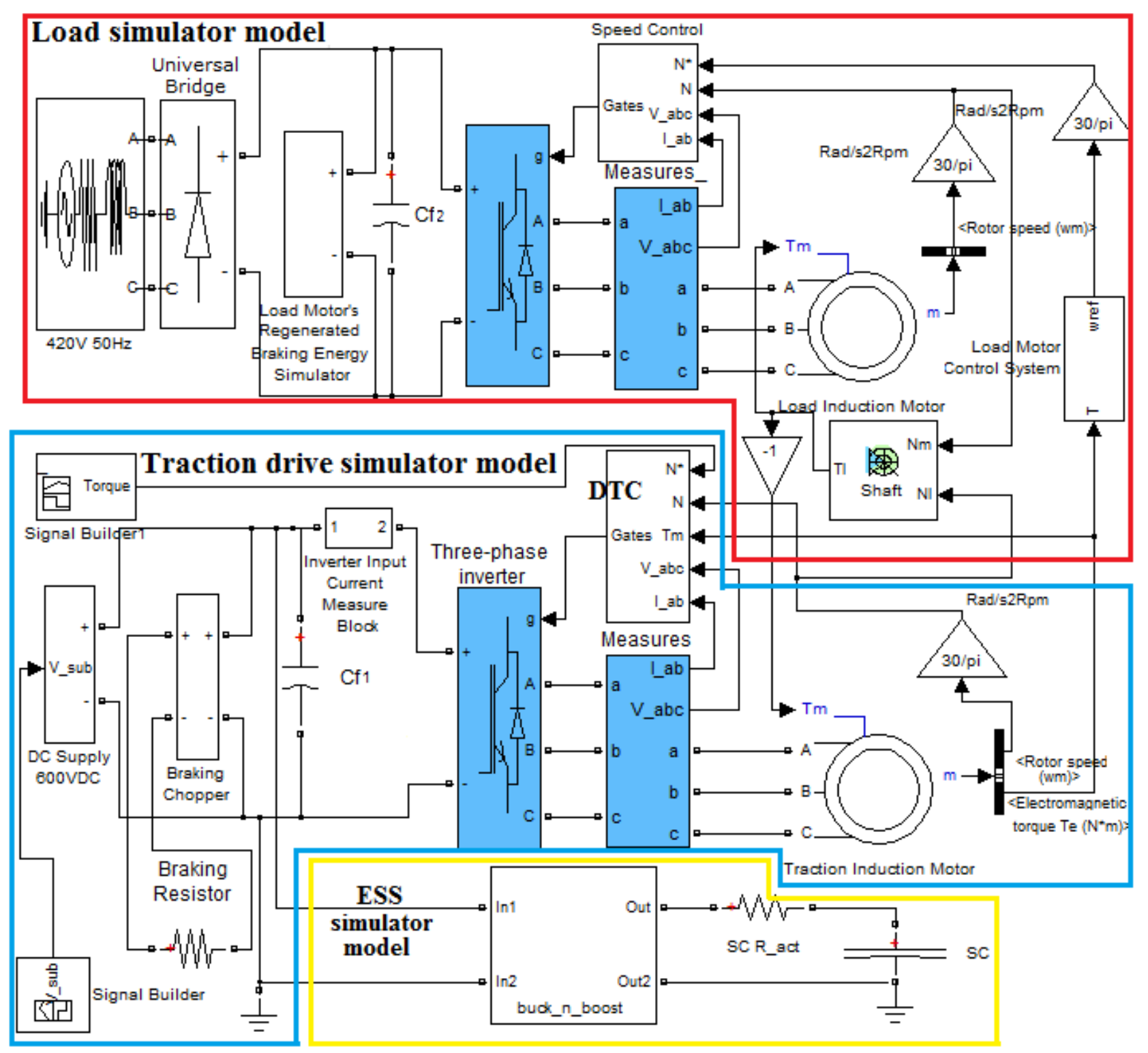

Fig. 3. Matlab/Simulink model of the traction drive test bench.

\section{MATLAB/SIMULINK MODEL}

Fig. 3 shows a simplified Matlab/Simulink model of the test bench. 600 VDC supply simulates DC supply grid in one case and substation in other case. Both load and traction motors are coupled together by their shafts. Braking chopper's set voltage is $680 \mathrm{~V}$. Filter capacitor's $C f_{1}$ initial voltage is $600 \mathrm{~V}$ and if it increases reaching $680 \mathrm{~V}$, the braking chopper will be activated.

DTC block of the traction motor contains several subsystems constructed basing on equations from the theory of DTC. The description of the load motor control system is given in [3]. Load simulator model contains 420 VAC source which is followed by a rectifier that is made to be irreversible in comparison to the proposed principal circuit shown in Fig. 1. In this model load motor's regenerated braking energy simulator operates on the same principle as traction motor's braking chopper with its braking resistor by imitating load motor's generated energy that is expected to be transferred to AC grid when performing experiments with real traction drive test bench circuit.

In accordance to the speed and torque of the traction motor the speed controller block controls the speed of load motor for loading the traction motor. The working principle of ESS simulator model's buck boost converter does not depend on traction drive principle, AC or DC, and is explained in [4].

\section{ESS SCALING}

SCs are considered to be a very promising technology for braking energy storage applications. Nevertheless there are still topical questions regarding more effective exploitation. The same energy storage components are frequently used for high power motors on EPT.

In [3] the scaling of $\mathrm{AC}$ bench is based on four-axle T3M type sized electric tram that might be equipped with $\mathrm{AC}$ 
traction drive. Tramcar parameters are as follows: vehicle gear box ratio $k_{\text {gear }}=7.36$; mass of an empty tramcar $m_{o}=18.5 \mathrm{t}$; mass of a full tramcar $m_{\max }=30.2 \mathrm{t}$; wheel diameter $D=0.7 \mathrm{~m}$. Tram vehicle mass includes not only the mass of people inside the tram but also the mass of the ESS which is $120 \mathrm{~kg}$ if two SC components are applied and $240 \mathrm{~kg}$ if four SC components are applied. Together with ESS converter maximum additional weight of tram should not be increased for more than $500 \mathrm{~kg}$. The tram is assumed to be equipped with four AC motors with the power of $50 \mathrm{~kW}$ for each wheel. Hence, the total rated power of the tram $P_{\text {nom,tram }}=200 \mathrm{~kW}$ and the power scale factor of the bench is estimated to be $k_{p}=26.7$.

In addition to further experiments, the tram is presumed to be not completely empty. The supercapacitor Maxwell BMOD-0063 P125 with rated capacitance $C=63 \mathrm{~F}$, rated voltage $V_{s c \text {,nom }}=125 \mathrm{~V}$ and mass $m=60 \mathrm{~kg}$ is applied. These energy storage components are applicable in real trolleybuses and trams for supplying the traction drive and for storing the braking energy. SC capacitance and rated voltage might be oversized by comparing them to the power scales of the laboratory test benches.

The goal of scaling is to find the lowest SC capacitance for reducing ESS size parameters if only emergency autonomous traction mode is required and fully autonomous operation for scheduled non-electrified routes is not demanded by the traffic operator. It means that different working voltage range and modified parameters of ESS should be adjusted, like storage maximum voltage $V_{S C \text {, max }}$, storage minimum voltage $V_{S C \text {, min }}$ and SC maximum current $I_{S C \text {, max }}$. For that reason ESS scaling is carried out. For the bench and its ESS scaling it is necessary to consider also other parameters of the tram that have to be investigated and equipped with ESS. Electrical parameters of the tram given in [6] are the following: $C_{E S S \text {,tram }}=33.3 \mathrm{~F}$; $V_{c, \text { max }, \text { ram }}=450 \mathrm{~V} ; I_{c, \text { max }, \text { ram }}=700 \mathrm{~A}$. Further scaling procedure is valid for the static mode because it does not relate to the drive inertia and other dynamics.

The typical limited autonomous traction speed is restricted up to typical value approximate $v=30 \mathrm{~km} / \mathrm{h}$ without field weakening mode for prolonging the autonomous mode performance. Such speed restrictions are also more and more introduced by Riga City Council to provide the safety of pedestrians and cyclists on narrow streets. The kinetic energy of the tram at the time of braking is calculated in [17]:

$$
E_{k}=\frac{1}{2} m_{\max } v^{2}
$$

According to (1) $E_{k}=1047.77 \mathrm{~kJ}$ for $v=30 \mathrm{~km} / \mathrm{h}$. If the tram reduces its speed from $v_{1}=30 \mathrm{~km} / \mathrm{h}$ to value $v_{2}=0$, theoretical amount of regenerated energy can be calculated as in [17]:

$$
\Delta E_{k\left(v_{2}-v_{1}\right)}=\frac{1}{2} m_{\max }\left(v_{2}-v_{1}\right)=\frac{1}{2} m_{T} \Delta v
$$

According to (2) $\Delta E_{k(v 2-v 1)}=125.83 \mathrm{~kJ}$. Minimum voltage of the tram with ESS is calculated as:

$$
V_{c, \text { min,tram }}=\frac{P_{\text {nom,tram }}}{I_{c, \text { max }, \text { tram }}}
$$

Power of the tram with ESS is calculated as:

$$
P_{E S S, \text { tram }}=V_{c, \text { min, } \text { tram }} \cdot I_{c, \text { max }, \text { tram }}
$$

Energy of the tram with ESS is calculated as:

$$
E_{E S S, \text { tram }}=\frac{\left(V_{c, \text { max }, \text { tram }}^{2}-V_{c, \text { min }, \text { ram }}^{2}\right) \cdot C_{E S S, \text { tram }}}{2}
$$

According to (3), (4) and (5) $V_{c, \text { min,tram }}=285.71 \mathrm{~V}$, $P_{E S S \text {, tram }}=200 \mathrm{~kW}$ and $E_{E S S \text {, tram }}=2020 \mathrm{~kJ}$.

The next step is to calculate the rated power of the bench with ESS and it should be less or equal to traction motor's rated power:

$$
P_{E S S, \text { bench }}=\frac{P_{E S S, \text { tram }}}{k_{p}}
$$

Energy of the bench with ESS is calculated as:

$$
E_{E S S, \text { bench }}=\frac{E_{E S S, \text { tram }}}{k_{p}}
$$

According to (6) and (7) $P_{E S S, \text { bench }}=7.499 \mathrm{~kW}$ and $E_{E S S \text {, bench }}=75.66 \mathrm{~kJ}$.

The SC maximum current $I_{S C, \max }=40 \mathrm{~A}$ is chosen to calculate its minimum voltage:

$$
V_{S C, \text { min }}=\frac{P_{E S S, \text { bench }}}{I_{S C, \text { max }}}
$$

According to (8) the minimum voltage $V_{s c, \min }=187.48 \mathrm{~V}$ and is greater than SC component's $V_{s c, \text { nom }}=125 \mathrm{~V}$. And also due to the traction drive simulator supply voltage of $600 \mathrm{VDC}$ the common voltage of energy storage components must be greater than $125 \mathrm{~V}$. That is the reason why it is necessary to connect another $\mathrm{SC}$ in series. In this case, the common rated voltage of two series of connected $125 \mathrm{~V} \mathrm{SCs}$ is twice higher and equals $250 \mathrm{~V}$. The test bench supercapacitor nominal voltage of $250 \mathrm{~V}$ is chosen to provide compatibility with another $250 \mathrm{~V}$ accumulator energy storage system that is planned for further research.

Unfortunately, the common capacitance $\mathrm{C}$ of such connection circuit is going to be less according to the following formula:

$$
\frac{1}{C_{S C 1}}+\frac{1}{C_{S C 2}}=\frac{1}{C}
$$

From (9) $C=31.5 \mathrm{~F}$. Smaller capacitance might worsen the efficiency of energy storage. In order to acquire the desirable 
capacitance of $C=63 \mathrm{~F}$ of $250 \mathrm{~V}$, two such branches should be connected in parallel thus totally using four SC components.

Maximum voltage of SC is determined by:

$$
V_{S C, \max }=\sqrt{\frac{2 \cdot E_{E S S, \text { bench }}}{C}+V_{S C, \min }^{2}}
$$

In (10) $C$ is the total capacitance of ESS. Further, two previously mentioned ESS implementation types are investigated. According to (10) $V_{S C \text {, } \max }$ varies in regard to capacitance $C$. For $C=31.5 \mathrm{~F} \quad V_{S C, \max }=199.85 \mathrm{~V}$ and for $C=63 \mathrm{~F} V_{S C, \max }=193.76 \mathrm{~V}$.

To make ESS work more efficiently and without fault, it is advisable neither to discharge SC voltage to complete minimum nor to charge it to complete maximum. There are two relays from which the first disconnects ESS charging when the SC voltage level reaches the permissible charging voltage $V_{S C \text {,max,off }}$ and the second disconnects ESS discharging when the voltage level reaches the permissible discharging

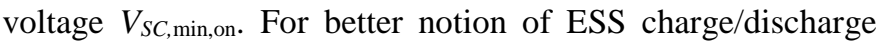
control, Fig. 4 shows the principle of SC ESS working voltage range. Working levels are adjusted by applying the hysteresis value that ensures the termination of SC charging $0.7 \mathrm{~V}$ under $V_{S C, \max }$ and discharging $0.7 \mathrm{~V}$ above $V_{S C \text {,min. }}$.

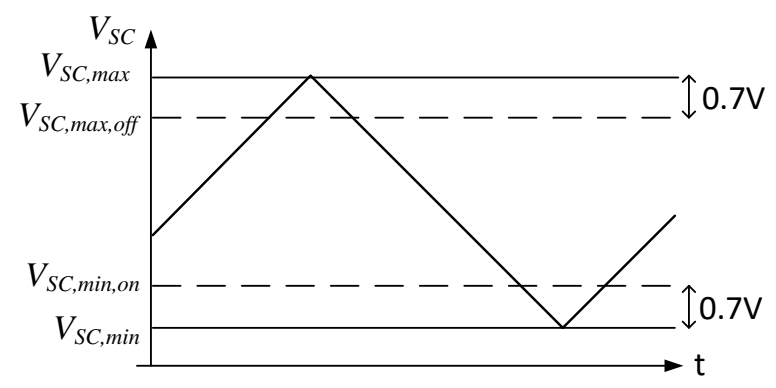

Fig. 4. Schematic of the SC working voltage range.

Table I numerically shows the SC ESS working voltage range for $I_{S C \text {, max }}=40 \mathrm{~A}$ depending on ESS capacitance $\mathrm{C}$ but $V_{S C(w)}$ are the initial $S C$ voltages chosen for further simulations.

TABLE I

$V_{S C}$ VAlues for DifFerent CAPACitances $C$

\begin{tabular}{|c|c|c|}
\hline \multirow{2}{*}{$V_{S C},(\mathbf{V})$} & \multicolumn{2}{|c|}{$I_{S C, \max }=40 \mathrm{~A}$} \\
\hline & $C=31.5 \mathrm{~F}$ & $C=63 \mathrm{~F}$ \\
\hline$V_{S C, \min }$ & 187.48 & 187.48 \\
\hline$V_{\left.S C_{(} W_{1}\right)}$ & 187.83 & 187.83 \\
\hline$V_{S C, \text { min,on }}$ & 188.18 & 188.18 \\
\hline$V_{\left.S C_{(} W_{2}\right)}$ & 189 & 189 \\
\hline$V_{S C_{(}\left(W_{3}\right)}$ & 193.67 & 190.62 \\
\hline$V_{S C}\left(W_{4}\right)$ & 198.15 & 192.06 \\
\hline$V_{S C, \text { max }, \text { off }}$ & 199.15 & 193.06 \\
\hline$V_{\left.S C_{(} W_{5}\right)}$ & 199.5 & 193.41 \\
\hline$V_{S C, \max (V)}$ & 199.85 & 193.76 \\
\hline
\end{tabular}

Five $V_{S C(w)} \mathrm{SC}$ common voltage initial values for further simulations were chosen as shown in Table I. $V_{S C(w 1)}$ is right between the voltages $V_{S C \text {,min }}$ and $V_{S C \text {,min, on }}$ but $V_{S C(w 5)}$ is right

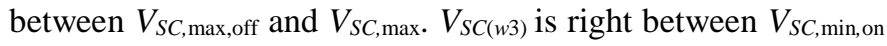
and $V_{S C \text {,max,off }}$ while $V_{S C(w 2)}$ is much closer to $V_{S C \text {, min,on }}$ and $V_{S C(w 4)}$ is closer to $V_{S C \text {, max,off. }}$

\section{Simulation RESUlts}

Previously in [3] the operational capabilities of AC bench both with and without ESS were tested. Although without any particular ESS scaling, overall it was verified that a real bench would be able to operate as such. Fig. 5 shows the characteristics of basic energetic parameters of the traction drive that are acquired by performing $25 \mathrm{~s}$ long simulation in all three sequential modes including $12 \mathrm{~s}$ acceleration (motor mode), $4 \mathrm{~s}$ freewheeling and $9 \mathrm{~s}$ braking (generator mode) where Speed is traction motor's developed rotation speed (rpm), $P \_$drive and $I$ _drive are traction drive power (W) and current (A).
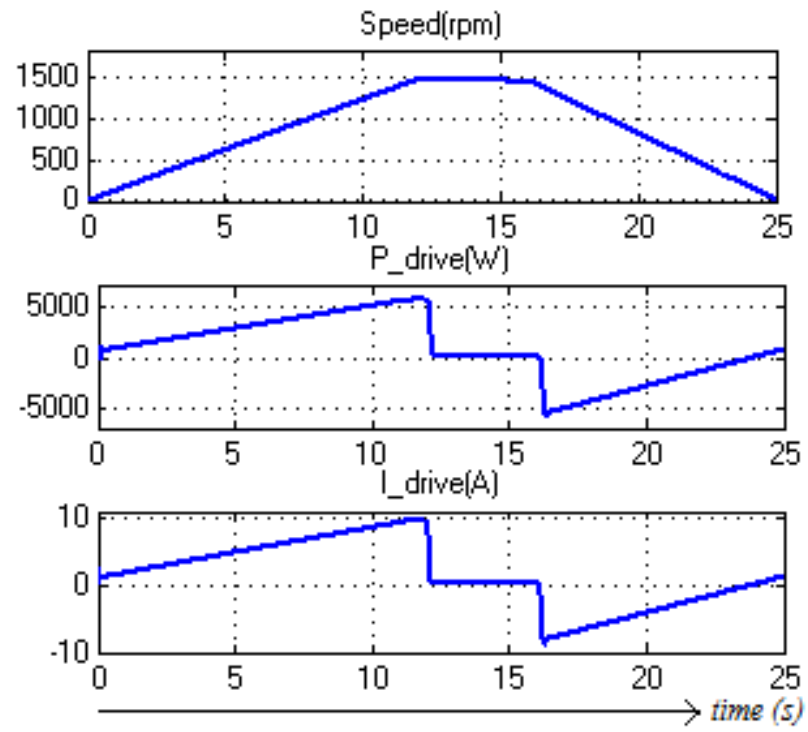

Fig. 5. Simulation diagrams of traction drive.

From Fig. 5 we can see traction drive motor's rotation speed which can be compared with tram's linear speed calculated by:

$$
v=\frac{3.6 \cdot \pi \cdot D}{60 \cdot k_{\text {gear }}} \cdot n=0.0179 \cdot n \quad[\mathrm{~km} / \mathrm{h}]
$$

When the maximum speed is achieved, $n=1550 \mathrm{rpm}$ and from (9) we can verify that $v=27.75 \mathrm{~km} / \mathrm{h}$. In daily situations, it takes approximately $12 \mathrm{~s}$ to reach the rated speed and 6-9 s to stop the tram by intensive electric braking [6]. As the vehicle speed is restricted up to rated speed, field weakening mode is not allowed. Therefore, without constant power mode simulation in traction drive constant torque mode which corresponds to tram's speed up to $30 \mathrm{~km} / \mathrm{h}$ becomes actual.

In order to secure the same speed of the traction machine for further simulations, there must be the same characteristics of power and current in the input of traction inverter. In motor 
mode the bench demands energy for acceleration and there are three possibilities of how it can be ensured. Electrical power can be supplied from substation, ESS or both of these power sources together. If both of them get disconnected during acceleration the traction motor does not accelerate anymore due to the insufficiency of power supply but keeps moving in freewheeling mode and the corresponding characteristics are not going to be like those shown in Fig. 5.

In relation to generator mode, there is an issue about the usage of braking energy. If ESS is disconnected or fully charged then braking energy is transferred to braking resistor and Fig. 6 shows the amount of power and energy lost when no ESS is applied. $P \_b r$ is traction drive's dissipated power (W) and $A \_b r$ is traction drive's dissipated energy (J).
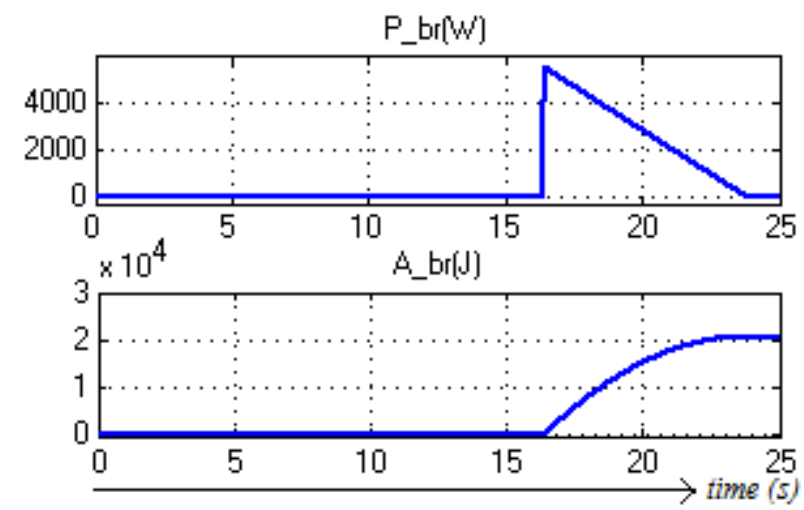

Fig. 6. Simulation diagrams of braking power and energy.

When M1 accelerates it spins M2 and Fig. 7 shows the power generated by M2 that is expected to be transferred to AC grid with 95-97\% efficiency due to losses in reversible rectifier.

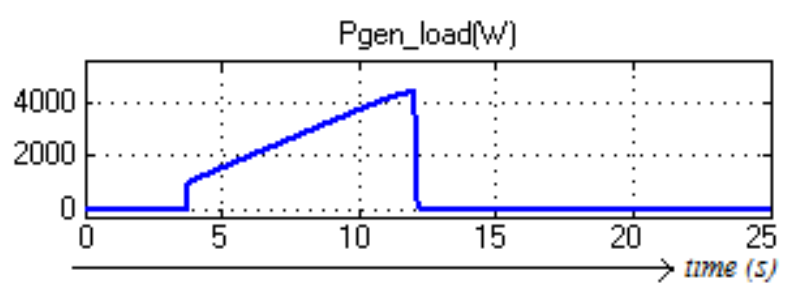

Fig. 7. Simulation diagram of load motor's generated power.

The key purpose is to regain the braking energy by storing it in SC of ESS. The goal of further simulations of the traction drive with ESS by getting the same traction drive characteristics shown in Fig. 5 is to investigate how the capacitance of ESS influences the working capability of ESS to supply the traction drive with power together with DC grid during motor mode and the efficiency of braking energy storing during generator mode as well as the possibility to perform all these given actions in autonomous mode without the contribution of DC grid.

Henceforward, in simulation diagrams $P_{-} s u b$ is substation's power (W), $V f$ is traction drive filter capacitor's voltage (V), $P \_b r$ is traction drive braking resistor's power (W), $V_{-} C$ is supercapacitors' common voltage (V), $P_{-}$drive is traction drive power (W) and $P \_$ess is power of ESS DC/DC converter looking from SC side (W).

\section{A. Simulations of Traction Drive Connected to DC Grid}

Taking into account the five chosen initial values $V_{S C(w)}$ of the SC locating in the working voltage range in Table I, five simulations were executed to compare how the capacitance influences the entire efficiency of ESS in a certain working voltage range. Acquired simulation diagrams show the comparison of efficiency between the highest and lowest capacitance values that are $31.5 \mathrm{~F}$ and $63 \mathrm{~F}$ accordingly.

When initial $V_{S C}$ is between $V_{S C \text {,min }}$ and $V_{S C \text {,min,on }}$ the power supply in motor mode must be ensured only by DC grid only. Fig. 8 and Fig. 9 show the simulation results of this case.
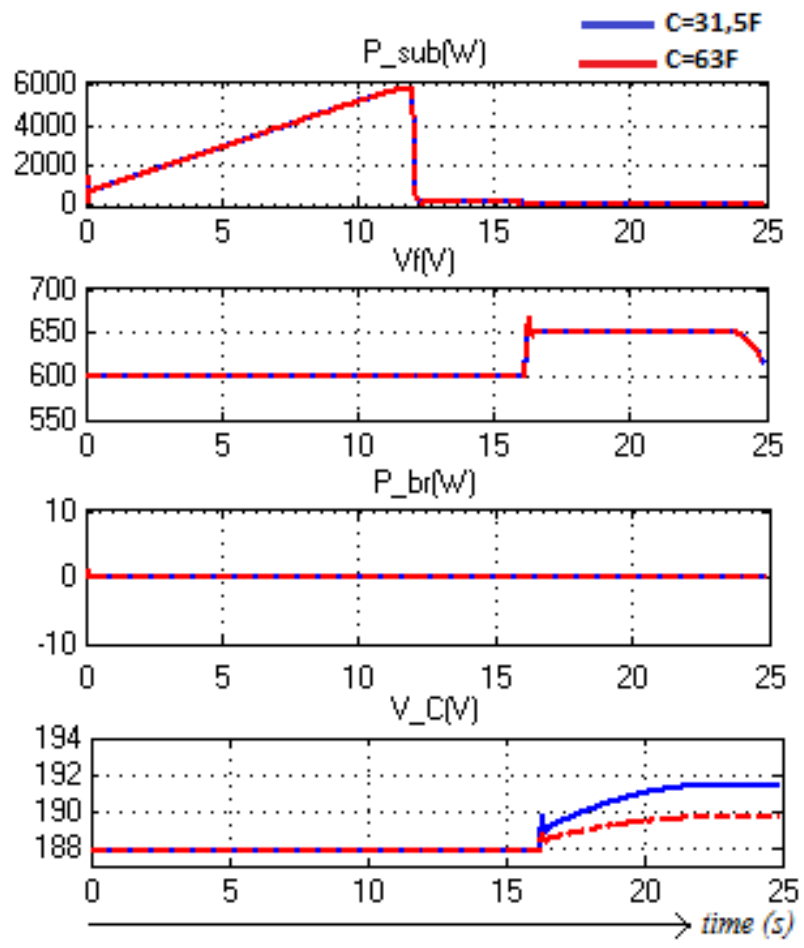

Fig. 8. Simulation diagrams for $V_{S C}=187.83 \mathrm{~V}$ for both $C=31.5 \mathrm{~F}$ and $C=63 \mathrm{~F}$.

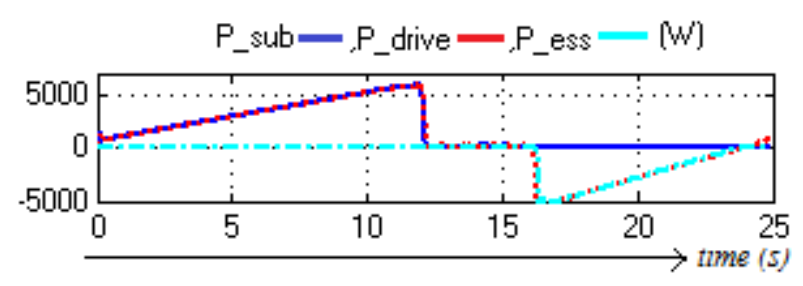

Fig. 9. Simulation diagram of power for both $C=31.5 \mathrm{~F}$ and $C=63 \mathrm{~F}$.

From Fig. 8 we can see that in braking mode, filter capacitor is supposed to be charged until its maximum voltage of $650 \mathrm{~V}$. Then the braking energy was transferred to ESS and braking resistor was not applied. The less the SC capacitance $C$ the faster $V_{S C}$ increases. Fig. 9 shows a foreseeable allocation of powers of substation, drive and ESS that were equal for both capacitances in this case. $P$ _drive is always the sum of $P \_e s s$ and $P_{-} s u b$. During the generator mode regenerated power is transferred to ESS as $P \_$drive and $P \_$ess lines overlap.

When initial $V_{S C}$ is slightly above $V_{S C \text {,min,on, ESS must ensure }}$ the power supply together with DC grid. It is predictable that 
ESS with lower capacitance might be able to perform it for shorter time. Fig. 10 and Fig. 11 show the simulation results.
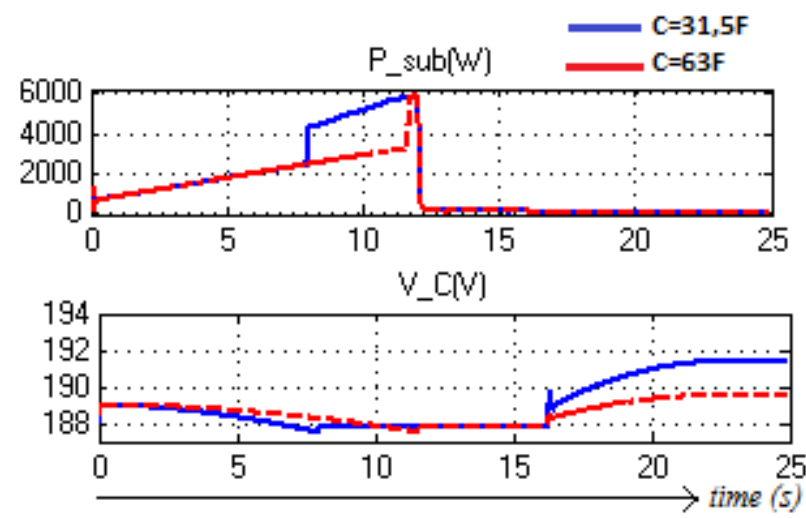

Fig. 10. Simulation diagrams for $V_{S C}=189 \mathrm{~V}$ for both $C=31.5 \mathrm{~F}$ and $C=63 \mathrm{~F}$

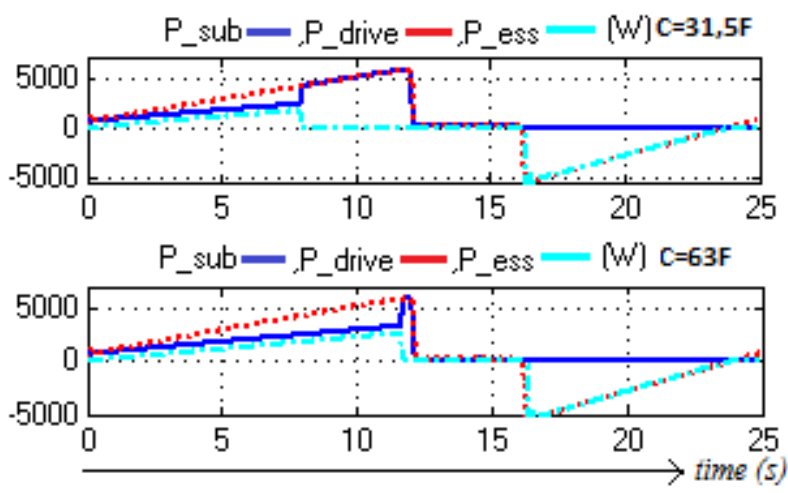

Fig. 11. Simulation diagrams of power for both $C=31.5 \mathrm{~F}$ and $C=63 \mathrm{~F}$.

From Fig. 10 we can see that ESS with the lowest capacitance discharges faster. On the other hand, ESS with higher capacitance is able to supply the energy for longer time although in the moment before the end of the motor mode it gets discharged as well. Braking power is fully transferred to ESS as we see in Fig. 11. So, ESS with the highest $\mathrm{C}$ is beneficial from acceleration mode point of view.

Simulation results when $V_{S C}$ is right in the middle between $V_{S C \text {, min,on }}$ and $V_{S C \text {, max,off according to voltage range for each }}$ capacitance are shown in Fig. 12 and Fig. 13.
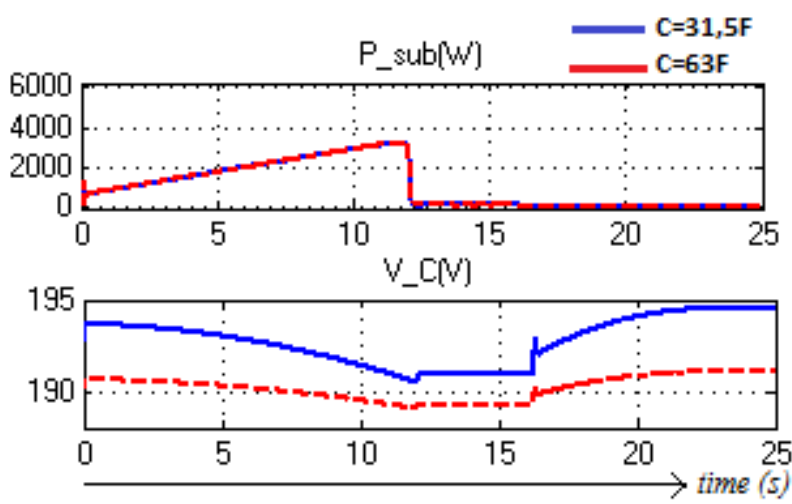

Fig. 12. Simulation diagrams for $V_{S C}=193.67 \mathrm{~V}$ when $C=31.5 \mathrm{~F}$ and $V_{S C}=190.62 \mathrm{~V}$ when $C=63 \mathrm{~F}$.

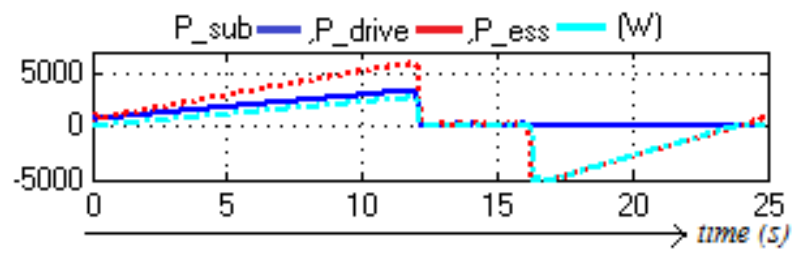

Fig. 13. Simulation diagram of power for both $C=31.5 \mathrm{~F}$ and $C=63 \mathrm{~F}$.

From Fig. 12 we can see that the traction drive in motor mode is supplied from both substation and ESS. Additionally, both ESSs were capable of supplying energy during whole traction mode and did not get discharged to minimum.

From Fig. 13 we can see that the braking energy is transferred only towards ESS and braking resistor is not applied at all. In this case, the ESS with the lowest $\mathrm{C}$ is more beneficial during both motor and generator mode.

Fig. 14 and Fig. 15 show the result of the case when $V_{S C}$ is slightly before $V_{S C \text {, max,off. }}$

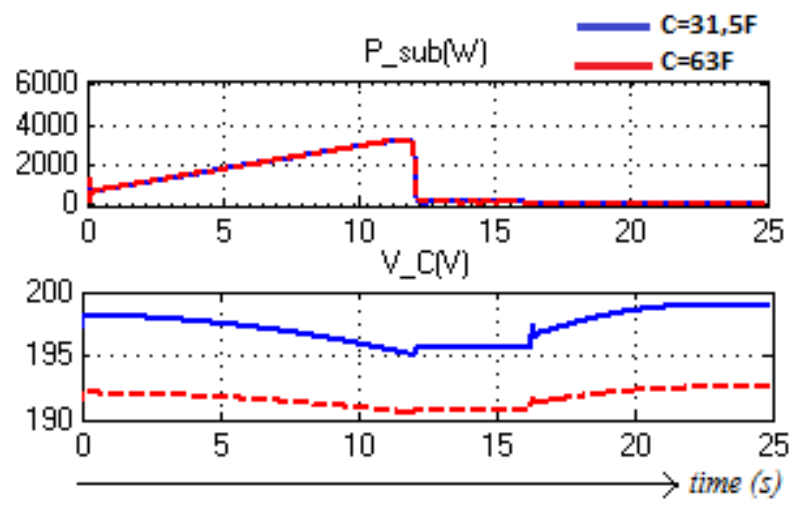

Fig. 14. Simulation diagrams for $V_{S C}=198.15 \mathrm{~V}$ when $C=31.5 \mathrm{~F}$ and for $V_{S C}=192.06 \mathrm{~V}$ when $C=63 \mathrm{~F}$.

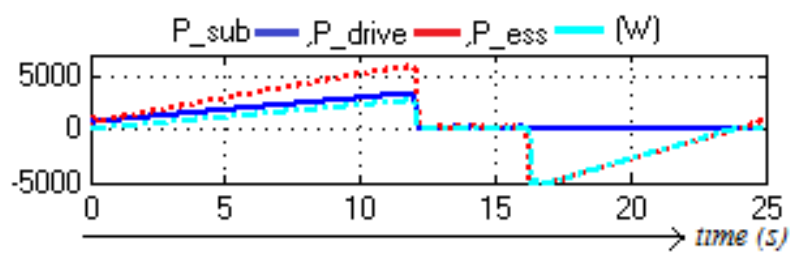

Fig. 15. Simulation diagram of power for both $C=31.5 \mathrm{~F}$ and $C=63 \mathrm{~F}$.

Fig. 14 shows that both highest and lowest capacitance ESSs do not get discharged until minimum during the motor mode and do not get charged until maximum during the generator mode just like previously in Fig. 13. ESS with the lowest $C$ is beneficial also in this case.

When initial $V_{S C}$ is right between $V_{S C \text {,max,off }}$ and $V_{S C \text {, max }}$ according to voltage range for each capacitance, it is predictable that during motor mode SC might not discharge enough to accumulate the whole braking energy during generator mode. Fig. 16 and Fig. 17 show the simulation results of this case. 

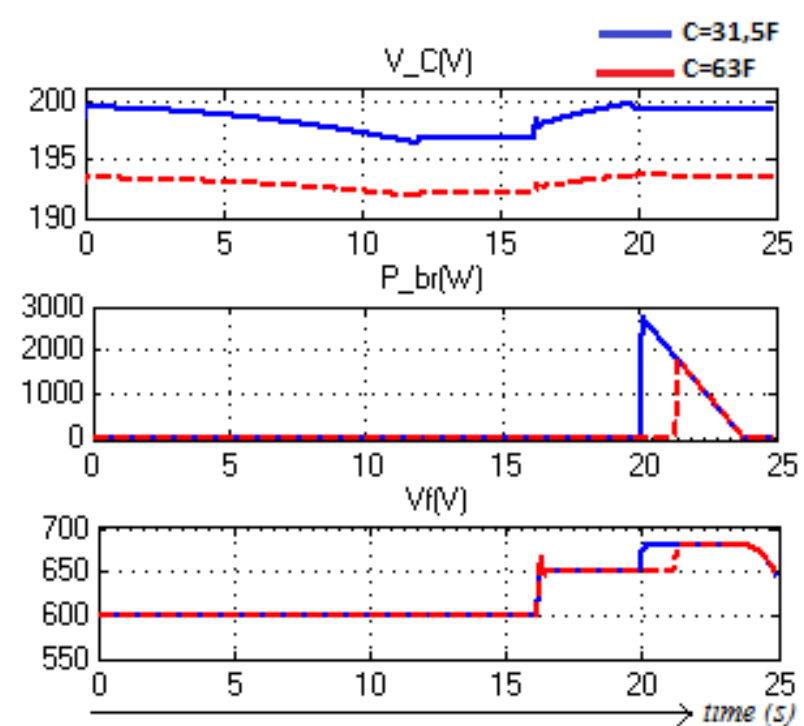

Fig. 16. Simulation diagrams for $V_{S C}=199.5 \mathrm{~V}$ when $C=31.5 \mathrm{~F}$ and $V_{S C}=193.41 \mathrm{~V}$ when $C=63 \mathrm{~F}$.

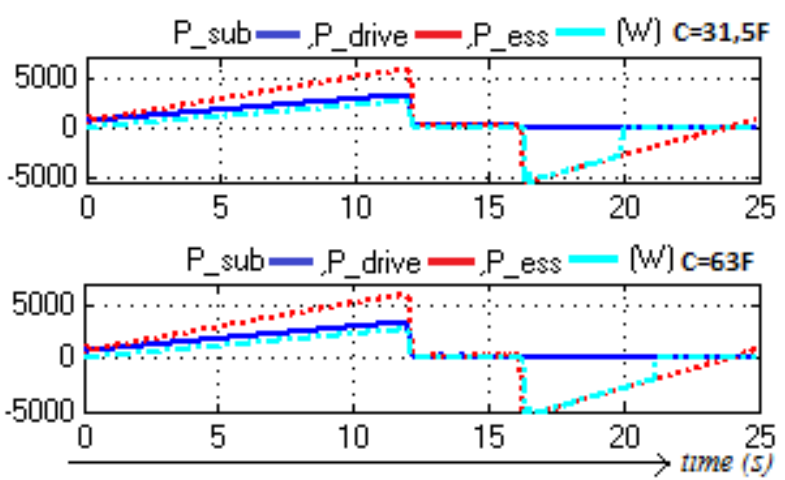

Fig. 17. Simulation diagrams of power for both $C=31.5 \mathrm{~F}$ and $C=63 \mathrm{~F}$.

From Fig. 16 we can see that as the initial $V_{S C}$ is above $V_{S C \text {, max,off }}$ there is no problem to discharge it to supply the traction drive with energy during motor mode. However, in motor mode ESS does not get sufficiently discharged. The smaller the SC capacitance the faster it recharges. Lower capacitance SC discharges faster, so the braking resistor is applied earlier. In this case, ESS with higher capacitance value is more beneficial from braking energy storing point of view.

\section{B. Simulations of Traction Drive in Autonomous Mode}

ESS is also supposed to supply the traction drive with energy in autonomous mode. In this instance, the initial common voltage of the SC should not be less than the average voltage $V_{S C(w 3)}$ from Table I, not to mention the coming to minimum voltage. Hence, two additional simulations for $V_{S C(w 3)}$, and $V_{S C(w 4)}$ were performed.

When the traction drive with ESS operates in autonomous mode, much faster ESS discharging during motor mode is predictable. Fig. 18 and Fig. 19 show the results when the common initial $V_{S C}$ is right between the $V_{S C \text {, min,on }}$ and $V_{S C \text {, max,off }}$ in autonomous mode
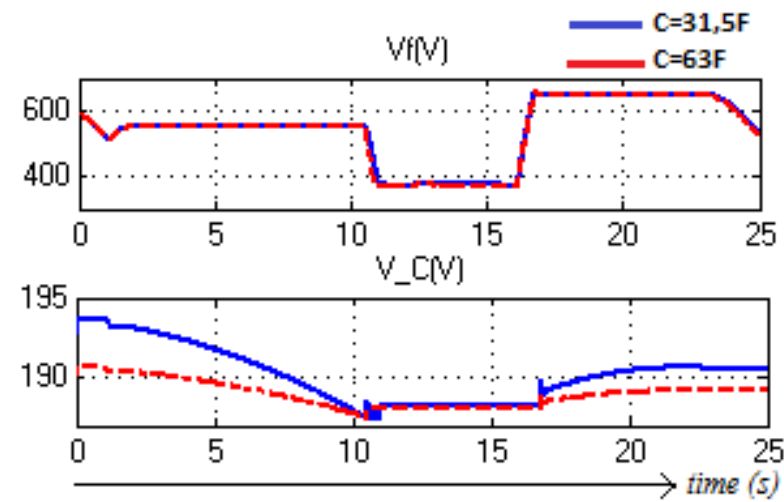

Fig. 18. Simulation diagrams for $V_{S C}=199.5 \mathrm{~V}$ when $C=31.5 \mathrm{~F}$ and $V_{S C}=193.41 \mathrm{~V}$ when $C=63 \mathrm{~F}$ in autonomous mode.

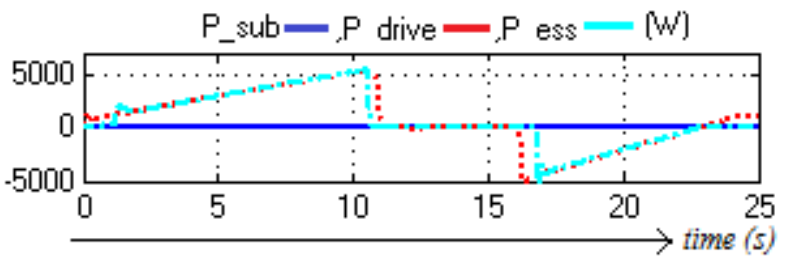

Fig. 19. Simulation diagram of power for both $C=31.5 \mathrm{~F}$ and $C=63 \mathrm{~F}$ in autonomous mode.

In the first moment of acceleration supply energy is taken from the filter capacitor and recharged to its minimum voltage by ESS. However, in the moment before acceleration ends the supply energy is taken from the filter capacitor as ESSs of both capacitances discharge to their minimum voltages.

Fig. 20 and Fig. 21 show the simulation results when the initial $V_{S C}$ is rather close to $V_{S C \text {, max,off. }}$

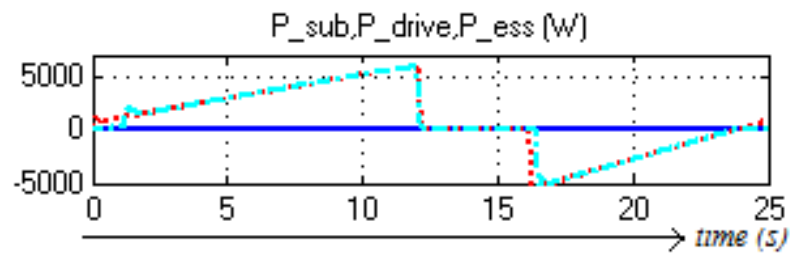

Fig. 20. Simulation diagram of power for both $C=31.5 \mathrm{~F}$ and $C=63 \mathrm{~F}$ in autonomous mode.
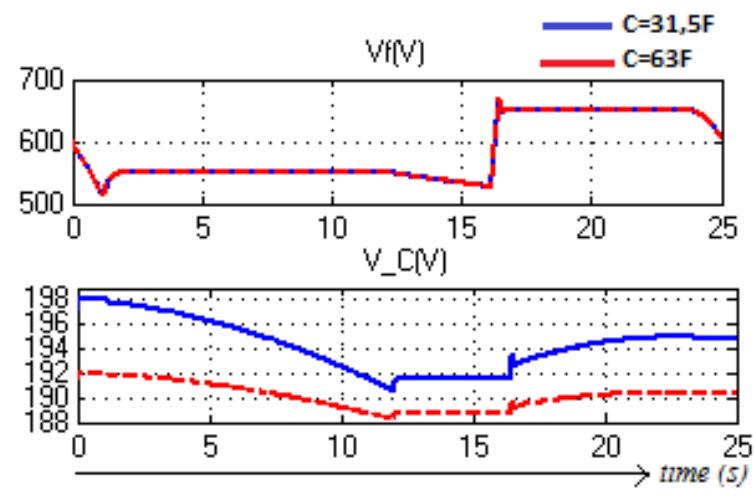

Fig. 21. Simulation diagrams of power for $V_{S C}=198.15 \mathrm{~V}$ when $C=31.5 \mathrm{~F}$ and $V_{S C}=192.06 \mathrm{~V}$ when $C=63 \mathrm{~F}$ in autonomous mode. 
From Fig. 20 and Fig. 21 we can see that ESS is able to supply the traction with energy during acceleration mode. It can be concluded that ESS with the lowest capacitance is more beneficial during autonomous mode.

\section{CONCLUSION}

Simulations of induction traction drive test bench model imitating the movement of tramcar on level surface in different ESS conditions is studied in this article.

If both the substation and ESS supply the traction drive with energy with the initial SC voltage being close to minimum the ESS with highest capacitance is more suitable. When the value of initial SC voltage is right from the middle until permissible charging voltage the energy supply for traction drive and braking energy recovery is ensured for ESSs of both capacitances. According to ESS application in autonomous mode, the initial SC voltage value should be from slightly above the middle until the maximum permissible voltage of the working scale.

In some instances, for providing correct simulations of traction drive operation modes on test bench, the recommended capacitance of ESS must be $63 \mathrm{~F}$, i.e. the highest value while in the majority of instances both ESSs operate equally efficiently, which makes the ESS with $31.5 \mathrm{~F}$, i.e. the lowest value preferable as it contains less physical components.

\section{REFERENCES}

[1] G. Zaleskis and V. Brazis, "The Efficiency Improving of Traction Drive Test Bench with Supercapacitor Energy Storage System," Journal of Mathematics and System Science, vol. 2, pp. 570-575, 2012.

[2] Zaleskis, G., Bražis, V., Latkovskis, L. "Estimation of Traction Drive Test Bench with Energy Storage System Operation in Regenerative Braking Mode," Electrical, Control and Communication Engineering. vol. 1, 2012, pp. 40-45. ISSN 2255-9140. e-ISSN 2255-9159. http://dx.doi.org/10.2478/v10314-012-0007-y

[3] G. Stana, V. Brazis, P. Apse-Apsitis, "Virtual Energy Simulation of Induction Traction Drive Test Bench," in IEEE $2^{\text {nd }}$ Workshop on Advances in Information, Electronic and Electrical Engineering (AIEEE 2014), Lithuania, Vilnius, 28-29 November, 2014, pp. 1-6. http://dx.doi.org/10.1109/aieee.2014.7020330

[4] U. Sirmelis, L. Grigāns, L. Latkovskis, "An Analytic Simulation Model for a Supercapacitor-Based Energy Storage System," in Proc. of the 14th European Conf. on Power Electronics and Applications (EPE 2011), Birmingem, United Kingdom, 30 August - 1 September, 2011, pp. 1-10,

[5] U. Sirmelis, "ESS Sizing Considerations according to Control Startegy," in 12th Int. Scientific Conf. "Engineering for Rural Development": Proc. vol. 12, Jelgava, Latvia, 23-24 May, 2013. Jelgava: Latvia University of Agriculture, 2013, pp. 346-351.

[6] Modernization with IGBT-Chopper of the Articulated Tramcars KT 4DMOD of the Thüringerwaldbahn und Straßenbahn Gotha GmbH, Leaflet No. 00 TG 2 DE.

[7] L. Latkovskis, V. Bražis, L. Grigāns, "Simulation of On-Board Supercapacitor Energy Storage System for Tatra T3A Type Tramcars," in Modelling Simulation and Optimization. G. Rey, L. Muneta eds. Sciyo: InTech, 2010. pp. 1-26. ISBN 978-9-5330-7048-3. http://dx.doi.org/10.5772/7669

[8] B. Destraz, P. Barrade, A. Rufer, M. Klohr, "Study and Simulation of the Energy Balance of an Urban Transportation Network," in 2007 European Conference on Power Electronics and Applications, 2-5 September, 2007, pp. 1-10. http://dx.doi.org/10.1109/EPE.2007.4417349

[9] R. Barrero, X. Tackoen, J. Van Mierlo, "Analysis and configuration of supercapacitor based energy storage system on-board light rail vehicles," in Power Electronics and Motion Control Conf. EPE-PEMC 2008. http://dx.doi.org/10.1109/EPEPEMC.2008.4635481
[10] L. Latkovskis, V. Bražis, "Simulation of Regenerative Energy Storage with Supercapacitors in Tatra T3A Type Trams," in 10th Int. Conf. on Computer Modelling and Simulation, Cambridge, United Kingdom, 1-4 April, 2008. pp. 398-403. http://dx.doi.org/10.1109/UKSIM.2008.38

[11] V. Bražis, G. Zal̨eskis, L. Latkovskis, L. Grigāns, "Traction Drive Load Simulator," in The 52nd Annu. Int. Scientific Conf. of Riga Technical University. Section of Power and Electrical Engineering: Abstract Book and Electronic Proceedings, Riga, Latvia, 14. October, 2011. pp. 68-69.

[12] L. Latkovskis, L. Grigāns, "Estimation of the Untapped Regenerative Braking Energy in Urban Electric Transportation Network," in 13th International Power Electronics and Motion Control Conference (EPEPEMC 2008): Proceedings, Poznana, Poland, 1-3 September, 2008. pp. 2066-2070. http://dx.doi.org/10.1109/EPEPEMC.2008.4635570

[13] L. Latkovskis, U. Sirmelis, L. Grigāns, "On-Board Supercapacitor Energy Storage: Sizing Considerations," Latvian Journal of Physics and Technical Sciences, vol. 49, no. 2, pp. 24-33, 2012. ISSN 0868-8257. http://dx.doi.org/10.2478/v10047-012-0009-1

[14] U. Sirmelis, L. Grigāns, "Capacitance Balancing for Supercapacitive Energy Storage System," in 10th International Symposium "Topical Problems in the Field of Electrical and Power Engineering. Doctoral School of Energy and Geotechnology II": Proceedings, Pernava, Estonia, 10-15 January, 2011. pp. 38-41.

[15] A.-L. Allègre, A. Bouscayrol, P. Delarue, P. Barrade, et al. "Energy Storage System With Supercapacitor for an Innovative Subway," IEEE Trans. on Ind. Electron., vol. 57, iss. 12, pp. 4001-4012, 2010. http://dx.doi.org/10.1109/TIE.2010.2044124

[16] Y. Cheng, J. Van Mierlo, P. Lataire, "Research and test platform for hybrid electric vehicle with the super capacitor based energy storage," International Review of Electrical Engineering (I.R.E.E.), vol. 3, N32008. pp. 466-478.

[17] J. Kubin, A. Richter, "Efficiency of Mechanical Energy Recovery from a Tram by Different Input Conditions," in $15^{\text {th }}$ Int. Power Electronics and Motion Control Conf., EPE-PEMC, 2012, ECCE Europe, Novi Sad, Serbia. http://dx.doi.org/10.1109/EPEPEMC.2012.6397229

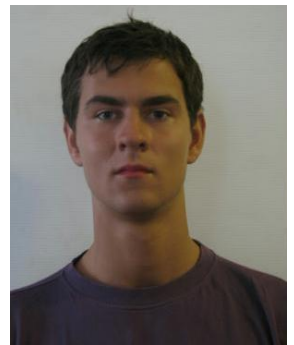

Girts Stana received the degree of Bachelor and Master in electrical engineering from Riga Technical University in 2013 and 2014 accordingly. He is presently a doctoral student and a research assistant with the Institute of Industrial Electronics and Electrical Engineering of Riga Technical University.

His main research interests are related to power electronics and electric drives.

$\mathrm{He}$ is a member of IEEE Latvia association. Address: Azenes Street 12/1, LV-1048, Riga E-mail: girtsta@inbox.lv

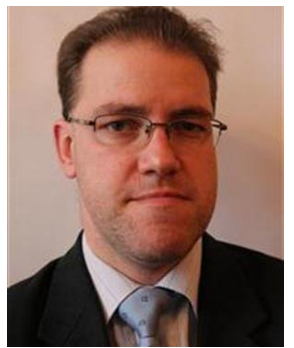

Viesturs Brazis, Dr. sc. ing., is an Associate Professor with the Institute of Industrial Electronics and Electrical Engineering of Riga Technical University. He received the degree of Master of electrical engineering from Riga Technical University in 2000. He received his Doctoral degree in 2005 from Riga Technical University.

His research interests are related to electric drives, power electronics and industrial automation. Address: Azenes Street 12/1, LV-1048, Riga E-mail: Viesturs.Brazis@ rtu.lv

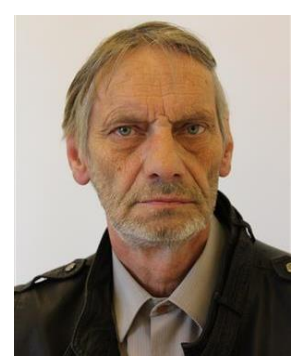

Peteris Apse-Apsitis, Dr. sc. ing., is a Lead Researcher with the Institute of Industrial Electronics and Electrical Engineering, Riga Technical University.

His main fields of scientific and research interests are connected with power electronics, robotics and mobile ICT applications.

$\mathrm{He}$ is the author of many industrial solutions and applications and patented inventions. $\mathrm{He}$ is a member of IEEE Latvia Association. Address: Azenes Street 12/1, LV-1048, Riga E-mail: Peteris.Apse-Apsitis@ rtu.lv 